University of South Florida

DIGITAL COMMONS @ UNIVERSITY OF SOUTH FLORIDA
Digital Commons @ University of

South Florida

$11-1-2016$

\title{
Implications to Public Transportation of Emerging Technologies
}

CUTR

Follow this and additional works at: https://digitalcommons.usf.edu/cutr_nctr

\section{Recommended Citation}

"Implications to Public Transportation of Emerging Technologies," National Center for Transit Research (NCTR) Report No. CUTR-NCTR-RR-2016-10, Center for Urban Transportation Research, University of South Florida, 2016.

DOI: https://doi.org/10.5038/CUTR-NCTR-RR-2016-10

Available at: https://scholarcommons.usf.edu/cutr_nctr/35

This Technical Report is brought to you for free and open access by the National Center for Transit Research (NCTR) Archive (2000-2020) at Digital Commons @ University of South Florida. It has been accepted for inclusion in Research Reports by an authorized administrator of Digital Commons @ University of South Florida. For more information, please contact digitalcommons@usf.edu. 


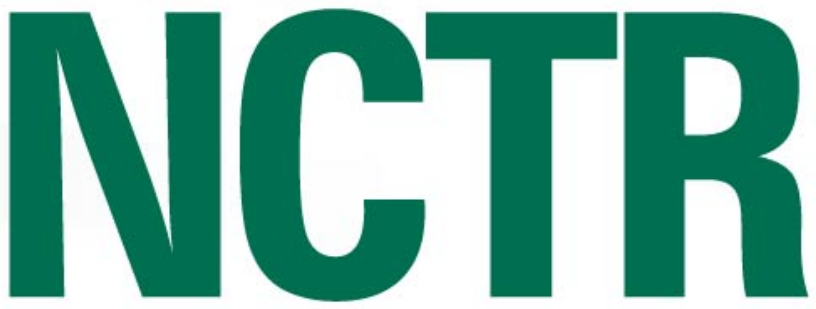

NATIONAL CENTER for TRANSIT RESEARCH

\section{Implications to Public Transportation of Emerging Technologies}

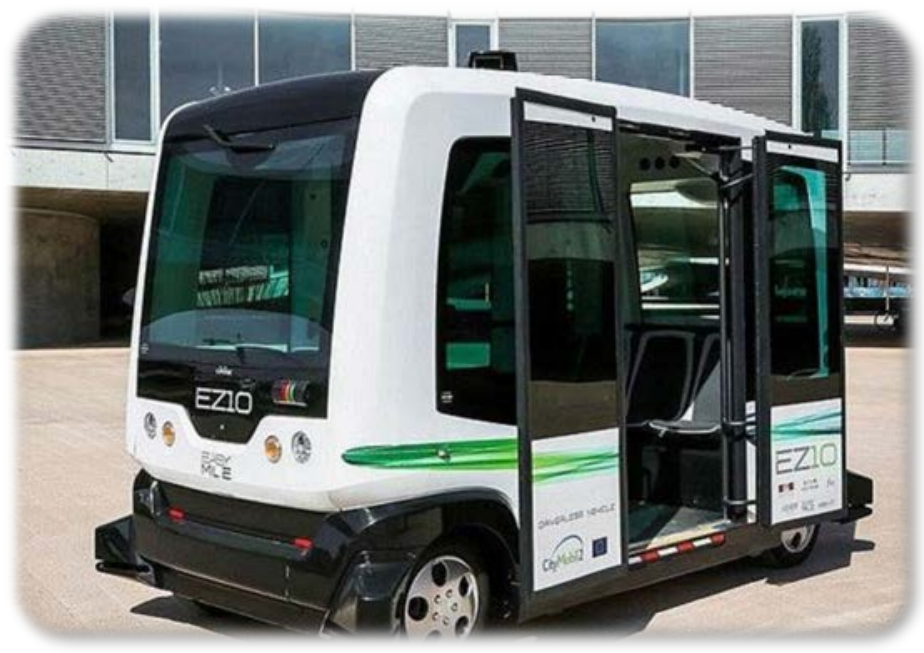

Steven E. Polzin, Ph.D. November 2016 


\section{Implications to Public Transportation of Emerging Technologies}

This paper follows up on a white paper authored in late 2013 titled "Implications to Public Transportation of Autonomous or Connected Vehicles." This paper updates thinking based on activities to date and specifically delves into how the public transportation industry might be impacted and could respond to this issue. The ideas and positions offered are those of the author and do not represent policy positions of the industry or any associated entities.

\section{Context}

Over the past two or three years, the emergence of new technologies impacting all travel modes including public transportation has garnered significant attention across the spectrum of interests, from the research and technology communities to the transportation planning and policy communities to the public, media, and political communities. This awareness and interest is evidenced by extensive media coverage and growing speculation on the implications on everything from roadway safety to the fate of traditional auto manufacturers to the consequences for mobility, the environment, land use patterns, and the economy.

Included in the list of potential consequences is the issue of the future of public transportation. Numerous authors have speculated on these consequences, with perspectives ranging from the demise of public transit as we know it, as automated on-demand vehicles replace traditional fixed-route services in all but the highest-volume corridors, to a resurgence of public transportation as technology renders personal auto ownership obsolete and public transportation complements the "mobility as a service" vision foreseen by some. Several of these perspectives are referenced in the bibliography.

This paper explores the issue by speculating on possible consequences associated with movement toward greater technology being integrated into vehicles and transportation systems. These observations draw from emerging discussions and reflect the perceptions and observations of the author. They are intended to seed discussion as they integrate knowledge of public transportation with various perceptions and expectations of how new technologies, including autonomous or connected vehicles, might become a significant component of personal mobility.

Some basic tenants of the technology induced changes in transportation are becoming increasingly clear:

- A spectrum of technologies is involved. The core technologies that enable meaningful changes in transportation include global satellite positioning, wireless communications, high-speed portable computer processing, sophisticated affordable sensing, battery power storage, and associated technologies and software, including machine learning, all of which are collectively influencing a multitude of aspects of transportation.

- Technologies are impacting all modes of transportation. The various technologies are influencing all modes of travel in ways that will impact their future competitiveness as their 
performance characteristics are changed by new technologies. Whereas those changes are readily apparent when one thinks about smartphone hailing of a transportation network company (TNC) vehicle or autonomous driving automobiles, technologies also are influencing all other modes of travel in a number of ways, complicating assessment of their relative attractiveness in the future.

- Technology is influencing multiple aspects of travel or engagement. Technology is influencing virtually all aspects of travel, from planning to payment to in-travel entertainment in addition to controlling vehicle functions. Technology has enabled electronic communications as a substitute for travel (e-commerce, distance learning, webinars, etc.), and expectations for virtual reality include the prospect of reducing the need for physical presence in more social interactions and activity functions.

- Technology-related influences on travel are impacting virtually all recognized travel characteristics that influence travel decisions. Cost in time and money, safety, convenience, reliability, comfort, flexibility, environmental impact, personal privacy and identity security, awareness of opportunity, image, and social interaction opportunities are influenced by the changes technologies are having on transportation options.

- Technologies are enabling a transformation of the historic business models and economic structure of transportation. Technology enables fundamentally different business structures and cost structures for travel with the prospect of sequentially and/or simultaneously sharing vehicles, reducing capital and operating costs, and transitioning transportation expenditures from high fixed and low variable costs characteristic of personal auto ownership to a fullyallocated per-trip cost structure. These technology-enabled changes are hypothesized to profoundly influence travel behavior.

- Technologies' impacts on transportation are occurring simultaneously with other changes in demographics and the economy that are influencing travel. Understanding the consequences of automation and technology deployment within transportation will be confounded by other changes in economic and demographic conditions that also are influencing travel behavior.

- The influence of technology on transportation will occur simultaneously with these same technologies, having potentially transformative impacts on other industries. Dislocations to businesses and labor and implications on consumer behaviors will not be restricted to transportation as automation and robot deployment impact multiple economic sectors. Thus, reactions to technology deployment in transportation may be influenced by consequences of, and reactions to, technology deployments in other sectors of the economy and society.

- The magnitude of the envisioned changes is such that estimating the ultimate technical/performance impacts and consumer reactions to them are subject to a great deal of uncertainty. The ultimate impacts on transportation will be influenced by the performance of 
the respective technologies in real-world applications, government and business strategies regarding regulation, governance, competition, etc., and consumer/customer responses. The nature and magnitude of the envisioned changes are such that there are no readily-available analogous contexts from which one can extrapolate consequences. Exceptionally talented and knowledgeable people have very different perceptions of timing of deployment and consequences.

- The impact on public transportation in a world moving toward autonomous vehicles is not wholly dependent upon the pace of technology development, business strategies, and consumer reactions. It also may be impacted by policy initiatives emerging from legislative and administrative actions of various levels of government. Policy initiatives, including but not restricted to regulation, may influence the timing and nature of the resultant impacts of technology on transportation. Some policy analysts feel policy initiatives will be critical to ensuring that the potential benefits from new technologies are realized by the broader public.

There are different definitions of public transportation, and the role of public transportation may evolve as technologies are increasingly deployed in transportation. Accordingly, a more prudent approach is to assess the implications of technologies on personal mobility and then explore how public transportation functions, facilities, services, and institutions will adapt going forward. Although public transportation as we know it today inevitably will change, and with those changes will be impacts on stakeholders, the core functions carried out by public transportation will, in all probability, continue to be carried out. The respective roles of the traveler, the private sector, and the public sector are anticipated to be changing.

When focusing on the impacts on public transportation, it is important to recognize there is no single definition of public transportation in the context of its role in overall personal mobility. The consequences to public transportation of technology deployment are dependent upon one's interpretation of the current and possible future roles of public transportation. Although classic issues associated with traditional public transportation are given the most attention, the discussion includes future roles relating to the provision of mobility that may envision or enable a redefinition of public transportation.

The consequences to public transportation of technology deployment are dependent upon one's interpretation of the current and possible future roles of public transportation.

\section{The Fundamental Changes in Travel Enabled by New Technologies}

Figure 1 characterizes how various new technologies can influence the factors known to effect travel behavior. Technologies can change the performance of a travel option with respect to many of the factors that transportation experts understand as critical influences on travel decisions. In addition to direct impacts, the technologies enable different business models for delivering transportation that fundamentally change the cost structure and, potentially, the price of travel. Not only are the features of the various travel options impacted by the technologies, but these technologies have enabled, in effect, new mode options for travelers. Table 1 outlines how technologies influence each of the decision 
choices in the traditional four-step process for characterizing travel decision-making. As pointed out, each decision is influenced in various ways, and, specifically, the choice of options is expanded broadly due to the ability of automation to make possible new modes/business concepts for delivering mobility.

\section{Figure 1. Technology Factors that Influence Travel Behavior}

$\checkmark$ Real-time information

$\checkmark$ Electronic payment

- Trip planning

$\checkmark$ Trip scheduling

- Navigation/trip tracking

Electronic hailing

- Sequential vehicle sharing

- Trip aggregating/ride matching

Dynamic pricing

Electronic satisfaction feedback

Automated driving

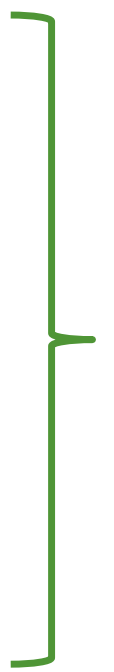

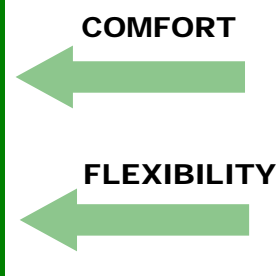

\section{ENVIRONMENTAL IMPACT}

CONVENIENCE

RELIABILITY

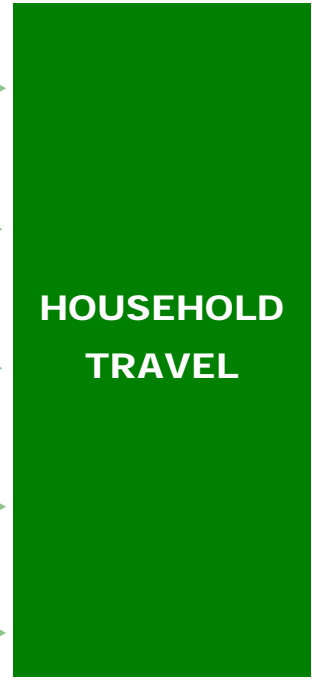

IMAGE

SOCIAL IMPACT

\section{Table 1. Traditional Travel Decision-Making as Impacted by Technologies (Four-Step Process)}

1. Number of trips made (trip generation impacted by communication substitution)

2. Destination choice (trip distribution impacted by better knowledge of choices)

3. Mode choice (expanded set of choices and changed characteristics)

- Drive personal traditional car

- Ride with family/friend

- Taxi

- Personal bike

- Transit

- Walk

- Hail alternatives transit (microtransit, Bridj, MetroBee, TransLoc, Via)

- Ridesharing - Carma, eRideShare

- Carsharing (Car2Go, Zipcar)

- Ride in personal automated car

- Hail automated car service

- Bikesharing
- Ridesourcing, e-hailing (Uber, Lyft, etc.)

4. Path assignment (path choice assisted by GPS, Digital mapping, and real time information)

The number of trips made is influenced by changes in travel choice attributes such as cost and by the ability to substitute communication for carrying out some of the activities that historically have required travel (e-commerce, distant learning, downloading print, video and audio content in lieu of travel, etc.). The choice of destination is aided by the opportunity to gather more complete information about destinations, such as determining the availability and price of a product before traveling to a retail location. The mode choice decision most obviously is impacted as many more technology-enabled mode 
and mobility delivery options are available that allow hailing vehicles, online payment, online trip planning, etc. Finally, trip path also is affected as real-time information and navigation provide distance-, time-, or cost-optimized travel paths.

As suggested by Figure 1 and Table 1, the influence of technology will be pervasive and multifaceted, with a host of interactions and, in many cases, unknown magnitudes of change and unknown behavioral response. For example, much of the excitement underlying investor interest in autonomous vehicles is premised on being able to deliver lower-cost mobility to customers by virtue of using the assets more effectively and capturing the benefits of logistics and safety improvements. Both the actual magnitude of potential cost savings and consumer valuation of those benefits in terms of modified travel behavior are being estimated but require extrapolation of other observed behaviors in the absence of the ability to measure changes based on actual deployments of the types of services envisioned. Thus, much of the current discussion of the impacts is speculative and based on various scenarios of deployment and behavioral responses. Given the importance of transportation and the transformative nature of changes hypothesized, this future scenario impact assessment strategy is prudent but remains highly speculative.

\section{The Critical Impacts of Technology on Transportation}

This section focuses on the key travel behavior decisions associated with technology deployment that likely will influence public transportation use. As noted, numerous factors interact in travel decisionmaking, and the collective impact of technologies on aspects of travel goes beyond those items given attention below. The referenced items are considered to be most critical in terms of their impact on travel behavior and subsequently public transportation. The categories relate to those factors shown in Figure 1 that influence travel behavior.

\section{How Will Automation Influence Travel Costs for Various Modes?}

Travel cost in time and money are acknowledged as the most critical factors in travel behavior. Automation technologies are predicted to significantly change travel costs in both time and money terms. In addition, the technologies enable a fundamental change in the cost/pricing structure for transportation that could diminish the mode bias implicit in the high-fixed-costs vehicle ownership model that dominates transportation spending for individuals.

For perspective, the Internal Revenue Service calculates auto operating cost per mile as \$0.54 in 2016; its estimate of variable cost is $\$ 0.19$ per mile. Based on the Consumer Expenditure Survey conducted by the US Bureau of Labor Statistics, on average, individuals spend approximately $\$ 0.48$ per vehicle mile to own and operate personal vehicles. Factoring in average occupancy reduces those costs to approximately $\$ 0.29$ per passenger mile of travel by auto. Nationwide passengers pay approximately 
$\$ 0.26$ per passenger mile in transit fares. ${ }^{1}$ The total average operating cost of providing transit is approximately $\$ 0.74$ per passenger mile; including capital costs increases it to approximately $\$ 1.08$ per passenger mile. ${ }^{2}$ Part of this differential between transit and auto is attributed to the fact that transit services are operated in urban areas where speeds are slower and costs are higher, whereas auto cost estimates are inclusive of all auto travel. In addition, there are other costs of auto operation not borne by users or not captured through traditional cost analysis (such as property taxes and other general revenues used to support transportation infrastructure investments as well as private investments such as parking facilities for customers and employees).

Fares of TNCs (Uber, Lyft, etc.) are in the range of $\$ 0.65$ to $\$ 2.00$ per mile; however, these fares fluctuate across time of day and location, by trip length, and by carrier and have varied dramatically over the past few years.

According to the Wall Street Journal, "Nearly everyone who has studied the subject believes these self-driving fleets will be significantly cheaper than owning a car, which sits idle roughly $95 \%$ of the time." ${ }^{3}$ Analyses are premised on fully-autonomous vehicles shared concurrently as apps aggregate trips going to similar destinations and shared sequentially as vehicles owned by mobility service providers serve multiple different customers throughout the day and are reported to be estimated to provide mobility for costs as low as $\$ 0.20$ to $\$ 0.50$ per passenger mile. It is the prospect of these cost differences that provides the expectation of the transformational effects envisioned from automated mobility.

Interestingly, automated vehicle operating costs are envisioned as being lowest in core urban areaslocations in which auto ownership and operating costs are highest and transit use is most productive. One might note that the actual cost per passenger mile for delivering automated services is highly dependent upon a host of assumptions covering everything from vehicle capital and operating cost to the extent of market penetration to the logistical efficiency of fleet management and customer acceptance of average wait times and shared vehicle use. Simple issues such as the trade-off between tolerable wait times and fleet size, the extent of the market that converts to automated vehicles, the size of reserve fleets, strategies for ensuring vehicle cleanliness, decisions on how many unique vehicle

\footnotetext{
${ }^{1}$ Per-mile VMT spending based on 2015 Consumer Expenditure Survey data and National Household Travel Survey household vehicle miles of travel estimates extrapolated to 2015. Average per-mile transit fare based on National Transit Data on gross fare revenues and gross passenger miles of service.

${ }^{2}$ Transit passenger miles operating and capital costs based on 2014 national total operating and capital expenditures and passenger miles as reported in APTA 2016 Transit Fact Book.

${ }^{3}$ Mims, C., "Driverless Cars to Fuel Suburban Sprawl: Research Suggests Advances in Transportation Technology Contribute to Bigger and More Sprawling Cities." Wall Street Journal, June 20, 2016.
} 
size/configuration options might be available to customers, vehicle parking and staging strategies, and other policy and logistics decisions ultimately will impact the cost of mobility via automated vehicles.

As important as the fully-allocated actual cost of travel to the consumer is the incremental cost for each trip. Travel behavior today for individual trips is highly influenced by household vehicle ownership. Inherent in the commitment to own a vehicle are a number of costs that are relatively fixed, including registration and licensing, a large share of insurance cost and vehicle depreciation, perhaps costs for garaging/parking, and some share of maintenance costs that are time- vs. use-related. Thus, when it comes to choosing the mode for an individual trip, the true marginal cost or out-of-pocket cost for a car owner is relatively modest-in the range of $\$ 0.10$ to $\$ 0.20$ per mile depending upon fuel efficiency, etc. The prospect of changes in the ownership model is likely to result in decisions on travel mode being based on total or closer-to-total cost per mile of travel. Thus, choosing transit at perhaps a $\$ 0.26$ per passenger mile fare cost is more attractive when one uses a $\$ 0.40-\$ 0.60$ per mile travel cost for personal vehicle use vs. a $\$ 0.10-\$ 0.20$ per mile marginal cost for personal vehicle use.

In addition to the prospect of lower costs for travel, full automation enables the traveler to use travel time to conduct other activities. There is utility to travelers in being able to accomplish these other activities during their travel-sleep, recreation (read, watch videos, play games online, etc.), work through voice or digital connections, etc. Although travelers do not have complete discretion as to what they can do during travel and components of the trip, such as accessing and exiting vehicles, which still consume some travel time, there is, nonetheless, incremental value to being able to do something with this time other than drive a vehicle.

Thus, there is a consensus of forecasts that there will be both money and time savings by virtue of automated vehicles, and, similarly, there is consensus within economic circles that lower-cost travel will result in greater consumption of travel-that is, travelers are anticipated to travel more as a result of lower time and money costs. The magnitude of this cost decrease may be offset partially if increased demand contributes to additional congestion beyond that which could be mitigated by automated systems. This increased demand also could impact non-exclusive guideway transit services if new demand is not offset by improved facility capacity enabled by automation, such as by reduced incidents, closer following distances, uniform vehicle flow optimization, intersection optimization, or technologyenabled increased ridesharing (vehicle occupancy).

Lower-cost travel options also are expected to increase the competition with public transportation as some share of travelers choose automated vehicle services in lieu of public transportation. Scenarios for automated vehicle travel cost are approximately consistent with current average fare revenue per passenger mile cost of approximately $\$ 0.26$ per mile. This equivalent cost could undermine transit ridership, particularly in markets in which transit services is not time-competitive, transit trip circuity is greater, or the share of the transit travel time that could not be used productively (boarding and alighting vehicles, transferring, standing vs. seated, etc.) is greater for transit travel than for automated vehicle travel. 
Even in the absence of automation, technology is enabling lower-cost travel options for purchased services. TNC services generally are priced well below taxi fares and, accordingly, are capturing some trips that alternatively might have been via public transportation. Preliminary data suggest that TNCs are capturing some trips from public transportation as well as complementing public transportation. ${ }^{4}$ Other technology-enabled travel options such as bikeshare, carshare, and dynamic ridesharing also are altering traditional travel behavior patterns. These travel options can both compete with public transportation and, in some contexts, serve as feeder/distributor services to line-haul transit to enable a car-free lifestyle that ultimately complements public transportation.

One implication of new travel options with different price points for travel involves the prospect that these services may cannibalize marginal transit services and further polarize public transportation ridership by siphoning off higher-income travelers who may be able to afford mobility services or automated vehicle services and, hence, give up or diminish their transit use. This could perpetuate the classic downward spiral in which lower productivity and fare revenues lead to additional service cuts that accelerate ridership declines. Additionally, as the constituency for public transportation potentially shrinks-particularly if it loses politically-active, more influential customers-it risks undermining

New mobility services may cannibalize marginal transit services and further polarize public transportation ridership by siphoning off higherincome travelers who may be able to afford mobility services or automated vehicle services. political support for public transportation spending.

Additional research and maturation of these service models will be required before a more fullyinformed assessment of how their cost points will impact public transportation can be determined.

\section{How Will Traveler Safety and Security Be Influenced by Technology-Impacted Travel Modes?}

Safety has long been a concern of travelers and includes safety from accidents when accessing or exiting a vehicle and during travel. It also includes personal safety from other individuals or risks when accessing or exiting a vehicle and during travel and can now be expanded to include personal security from unauthorized release of personal information that may subsequently jeopardize the traveler's wellbeing. Passengers ultimately will want to know how security incidents will be handled in shared-ride modes and what reporting/monitoring/response mechanisms will be in place for addressing passenger conflicts in vehicles without a driver. Although the public is amazingly tolerant of the less-than-stellar safety record of private vehicle use, sensitivity to security and safety in public modes or procured services generally are greater.

A widely-touted benefit of automated vehicles is the improved safety from accidents anticipated, with the frequently-repeated reference to $90 \%$ of accidents being attributable to human error. The implicit presumption is that a significant share of those incidents could be mitigated with technology-enabled

\footnotetext{
${ }^{4}$ Rayle, L., D. Dai, N. Chan, R. Cervero, and S. Shaheen. 2016. "Just a Better Taxi? A Survey-Based Comparison of Taxis, Transit, and Ridesourcing Services in San Francisco." Transport Policy, 45: 168-178.
} 
vehicle operation. If significant safety benefits are realized, they could translate into additional travel cost savings as insurance costs decline from their current average of approximately $\$ 0.075$ per mile ${ }^{5}$. Similarly, they could further the disruptive impact of these modes as healthcare and legal professions are impacted. The mitigation of accidents also has the prospect of increasing facility capacity, as incident congestion is a significant contributor to total vehicle delay.

Security sensitivities also are associated with automated vehicles, as they constitute an additional opportunity for illegally obtaining personal information that would constitute identity theft and its associated implications. Additionally, there is growing awareness of the criticality of ensuring that automated vehicles cannot be hijacked to cause disruption during travel or be used as tools in terrorism. Both the actual safety experience that accumulates as these modes mature and the public's response to safety performance remains to be seen.

\section{How Will Travelers React to Changes in Convenience, Reliability, Comfort, and Flexibility Associated with Automated or Mobility as a Service Opportunities?}

Consumption of any product is influenced by the extent to which consumers are aware of that product and the convenience with which they can acquire it. Just as the internet has made online shopping for products-particularly rare products-far more convenient, so, too, have web- and smartphone-based apps enabled travelers to have more convenient access to information about travel options. This extends to an ability to understand choices, plan specific itineraries, make payments, and provide feedback. This electronic information availability breaks down historic dependence on sustained market presence, the physical presence of mode options, and traditional marketing and enables intermodal integration and multijurisdictional or public/private service coordination in ways not previously conveniently available. Convenience is further enabled by cross-geography standardization in which apps such as OneBusAway and Uber work across communities. The same core technologies enable improved service reliability for both private vehicles and public transportation by virtue of features such as real-time monitoring of vehicle systems, improved passenger safety, and in-vehicle communication/ entertainment opportunities.

Less understood are how other aspects of the travel experience will be impacted with automated vehicles for individual trips or group travel: What capability will these means of travel have to respond to real-time changes in plans (young child needs to use a restroom ASAP, traveler wants to change destinations)? How will pricing and payment work for groups of travelers traveling together? How will an item left in the vehicle be retrieved? Can vehicles be retrained for a multi-stop trip tours? Are child seats available? What size vehicles will be available to handle larger families or groups? These myriad details ultimately will affect the perception of attractiveness of the travel option. Also unknown is the

\footnotetext{
${ }^{5}$ Insurance cost per mile approximates $\$ 0.075$ though is highly variable based on use, coverage and risk profile. http://newsroom.aaa.com/2015/04/annual-cost-operate-vehicle-falls-8698-finds-aaa-archive/
} 
level of vehicle reliability, particularly the sensitivity of the vehicles to continued operations in inclement weather or when subjected to non-routine operating conditions.

Market context, business strategies, and technology features may play a role in resolving numerous issues such as these that characterize the overall travel experience and the subsequent attractiveness of a given travel option. The willingness of travelers to transition from current travel modes, including public transit and, most specifically, from personal vehicle to mobility service or automated shared vehicles is likely to be influenced by the myriad characteristics of future travel options.

\section{How Will Environmental and Social Impacts and the Image of Technology-Enabled Mobility Impact Travel Behavior?}

Travel decisions are influenced by people's perceptions of and perhaps the reality of the social and environmental consequences of one's means of travel and their subsequent impact on one's image. The infamous love affair with the automobile and its cultural role as a status symbol inevitably will influence the adaption of alternative means of travel. Personal travel via owned vehicles has enabled travelers to adapt the level of comfort, image, personal space, storage space, group size/capacity, and other features to accommodate personal preferences and budgets. Everything from vehicle temperature to audio system volume and channel selection can be controlled by the individual. Individuals even can modify their safety risk by virtue of vehicle selection and operating decisions. In shared or automated modes, some of these opportunities will be more limited. In addition, vehicle selection often has been used to communicate status or values (luxurious, sporty, rugged, cool, cutting-edge, energy-efficient, safe, etc.).

The current assumption of many writing about automated vehicles is that they inherently will be energyefficient and, accordingly, environmentally-benign. A host of factors, from electrical propulsion systems to energy-optimized driving behaviors (braking and acceleration rates) to optimization of travel paths to reduced vehicle weight through optimal sizing and vehicle design, contribute to the expectations of energy-efficient mobility. In addition, the prospect of convenient vehicle sharing and, hence, higher occupancy rates and optimized roadway flow patterns also can contribute to operating efficiencies. However, offsetting factors might include extensive deadhead operation as empty vehicles shuttle between assignments, additional trip circuity as vehicles attempt to aggregate multiple travelers to increase vehicle utilization, and induced travel as the diminished cost and burdensomeness of driving increases tolerance for longer trip distances or more trips. The net impact remains unknown at this point in time.

There is also speculation of potential social implications of mobility as a service and automated mobility capabilities. The extent that these services offer attractive alternatives for segments of the market able to afford them creates a risk that the transit market will be further polarized, with those travelers having the resources to pay market prices

The mobility-as-a-service concept envisions a far more substantial role for either the private sector and/or a government agency to be the dominant provider of mobility vs. the selfreliance on oneself or one's household as the dominant supplier of mobility. 
for mobility services and the banking and technology capabilities to secure the services abandoning traditional public transit services. This risks further cultural polarization by means of travel, which may impact the image of both mobility services and public transportation.

Finally, the mobility-as-a-service concept envisions a far more substantial role for either the private sector and/or a government agency to be the dominant provider of mobility vs. self-reliance on oneself or one's household as the dominant supplier of mobility (vehicle ownership) in the current model. Some share of the public will be resistant to a greater dependency on either government or the private sector, perhaps a monopoly, as their source of mobility. This will create fear and distrust among some and raise questions such as how quickly will service be available in emergency conditions, who will get the available vehicles when it is time to evacuate for an emergency, how can one be assured that there will not be abusive pricing when monopoly conditions exist, will someone be denied services if they are behind in payment, will the service provider reveal travel information to other parties, etc.

The pace and magnitude of transition to a culture of shared mobility or mobility as a service will be influenced by how travelers perceive and respond to these conditions as well as technology, economic, and policy considerations.

\section{Implications of Mobility as a Service and Automation Technologies on Public Transportation}

The spectrum of behavioral changes noted above will have significant implications on public transportation as we know it. The balance of this paper explores some of the critical issues associated with shared mobility and automation in the context of their impact on public transportation. Public transportation is predominantly an urban mode, and, hence, this exploration of the impacts of autonomous or connected vehicles on public transportation focuses on how this technology revolution will impact urban transit travel.

As noted in the bibliography, a host of media, researchers, and practitioners have commented on potential implications of the integration of automation technologies in transportation on public transportation as we know it. Not surprisingly, prognosticated scenarios of the future are wide-ranging, with many envisioning technology deployments as complementary to public transit and others anticipating the demise or replacement of much of public transit. Most acknowledge the high degree of uncertainty that exists regarding both the pace at which new technologies influence transportation and the nature and extent of these impacts.

\section{Integrating New Technologies within Public Transportation}

\section{Public Transit as a Testbed for Technology and Automation Deployment}

Initial technology industry focus on deployment of new technologies for transportation predominantly targeted personal vehicles and trucks due to the massive global market potential of that opportunity. However, the institutional environment of public transportation, the high use and exposure of public transit vehicles, and the professional operator and maintenance environment make them attractive 
testbeds to deploy emerging technologies within the public transportation industry. The desire to improve public transportation performance and safety for vehicles accommodating groups of public passengers can help justify the policy, investment, and regulatory changes that may be necessary to facilitate such deployments. The fact that operator labor is a majority factor in overall bus transit operating costs provides further motivation for transit industry engagement to help enable the prospect of fully-automated vehicle operations in the future.

Various pilot projects, demonstration projects, and early deployments provide learning opportunities for individual agencies that can be shared with the industry, create a positive progressive appearance for public transportation, and create an opportunity for technology to benefit the industry and its customers. Although automatic vehicle operation attracts the majority of attention, new technologies have been and are continuing to be deployed within public transportation for the benefit of passengers and the industry. Innovations in fare collection and payment, passenger counting, trip planning and real-time passenger information, in-vehicle camera/security systems, remote vehicle operation monitoring, and various driver-assist technologies/systems are being deployed across the country and offer customer and agency benefits as well as learning experiences that help position agencies for the inevitably more technology intensive future.

Various pilot projects, demonstration projects, and early deployments provide learning opportunities for individual agencies that can be shared with the industry, create a positive progressive appearance for public transportation, and create an opportunity for technology to benefit the industry and its customers.

It is common for public transit buses to be in service $35,000+$ miles per year and in operation $2,500+$ hours annually. They often operate in urban environments with high interaction/risk opportunities with other vehicles, pedestrians, and bicyclists and typically carry passenger volumes several times higher than an average automobile-factors that make them attractive and appropriate laboratories for early deployment opportunities for safety-enhancing vehicle technologies. Transit agency environments with professional operators and dedicated maintenance professionals provide appropriate controlled environments for demonstration technology deployment and monitoring.

\section{Technology Deployment Market Opportunities in Public Transportation}

As noted, technology deployment continues within public transportation in a variety of ways, each affecting aspects of the mode's appeal and performance. Much of the early discussion regarding public transportation and technology deployment has centered on the impact of TNCs as competitors and complementary services and the prospects of fully-automated vehicles both integrated within public transit fleets and potentially replacing the need for public transit in certain markets. Several of these service concepts are discussed briefly below.

First-mile/last-mile complementary TNC and small vehicle services - A host of transit agencies across the globe are experimenting with a variety of technology-enabled service concepts intended as first-mile/ last-mile or feeder-distributor services to line-haul transit systems. Leveraging technologies 
offers an opportunity to reduce the cost of fixed-route and historically-inefficient feeder-distributor services, leveraging the logistics and communication/scheduling capabilities enabled by technology. Extensive experimentation will provide a growing body of experience that can be the basis for planning better public transit connections in new market areas and perhaps a more effective and efficient alternative for traditional transit services in low- to moderate-density environments that do not support efficient fixed-route or big-bus services. Initially, these services might include TNCs, real-time ridesharematching services, and short-term car rental and bikeshare services and, ultimately, may include automated vehicle services.

Of particular interest will be discerning what contexts enable first-mile/last-mile services to be complementary and in which environments they are competitive. This author's opinion is that these services will be supportive of longer distance line-haul premium transit services but competitive with urban circulation services. It also will be important to determine what level of investment in supporting complementary services is prudent within the spectrum of opportunities to improve transportation service. Specifically, how does subsidizing first-mile/last-mile services compare to traditional opportunities to improve ridership via reduced fares, better frequency, better coverage, expanded hours of operation, etc.

Automated bus opportunities - There is a compelling case to be made for automation within public transportation premised on the remaining a market for larger passenger vehicles to play a significant role in urban mobility. The criticality of operator costs as a constraint to the amount of public transportation service that can be afforded provides a compelling case for vehicle automation premised on it being able to substantially reduce the cost of providing public transportation services. Bus services constitute slightly less than $50 \%$ of all public

NTD reports approximately 200,000 bus operating employees for fixed route services and an additional 100,000 employees for demand responsive services. transit trips, a share that has been declining over time. They constitute approximately $38 \%$ of public transit passenger miles and generate 2.52 passenger boardings per revenue mile of service, with average vehicle occupancy of 10.7 passengers. The American Public Transportation Association (APTA) synthesis of the National Transportation Database (NTD) reports approximately 200,000 bus operating employees for fixed-route services and an additional 100,000 employees for demand-responsive services, with more than 1,000 agencies providing bus transit services. The Federal Transit Administration (FTA) NTD analysis indicates that bus operator compensation constitutes approximately $42 \%$ of bus operating expenses. 
The prospect of automating some or all fixed-route and demandresponsive bus services provides a significant financial opportunity for public transit agencies to reduce operating costs, which creates the opportunity to redeploy those resources on more service. Beyond the obvious opportunity to directly reduce costs, automated vehicles provide an opportunity to substantially restructure the nature of public transportation services. Part of the motivation for large vehicle sizes is to increase productivity per operator by virtue of being able to accommodate more passengers per operator. When unburdened by operator costs, the optimal vehicle size to best accommodate the

When unburdened by operator costs, the optimal vehicle size to best accommodate the volume of passengers and frequency of service that the market finds most attractive might well favor smaller vehicles running at higher frequencies. volume of passengers and frequency of service that the market finds most attractive might well favor smaller vehicles running at higher frequencies. Such a service concept might substantially increase the overall appeal of public transportation services. In addition, removing operator costs, coupled with lower operation costs associated with smaller vehicles, would make public transit service more viable for off-peak service times during which large vehicle capacity is unnecessary, yet the presence of service provides an important mobility opportunity for transit dependent travelers.

Although bus services are the logical market to evaluate for alternative automated services, there are places and times of day in which rail services might be more efficiently served by automated vehicle services as well.

Premium transit service via leveraging automation - High-performance public transportation typically has involved services that operate at relatively higher travel speeds that are more competitive with private vehicle travel. This higher speed traditionally is attained through capital investment in right-ofway and infrastructure that enables at least partially-exclusive travelway operations so as to avoid congestion and interactions with other roadway vehicles. Most often, this has meant rail systems and/or exclusive-lane bus rapid transit (BRT) facilities. Because of the inherent expense of providing the rightof-way and infrastructure required for exclusive travelway/ grade separation, these higher-speed, higher performance systems have been restricted to high-volume locations where the investment could be amortized over higher volumes of passengers. Automation provides an opportunity to ensure highperformance/higher-speed operations by leveraging technology rather than expensive infrastructure, as the technology can provide priority to public transit vehicles and/or ensure high-speed operation

Automation provides an opportunity to ensure highperformance/higher-speed operations by leveraging technology rather than expensive infrastructure. through roadway pricing or other treatments. In a fully-managed transportation network, public transit vehicles could be given appropriate priorities to ensure highspeed operation without dependence on guideway infrastructure. This has the opportunity to dramatically expand the range of potential applications of high-quality public transit service and/or reduce the capital cost and other constraints that heretofore limited the opportunity for high-quality transit services. If computers and sensors rather than tracks are guiding vehicles and if technology rather 
than grade separation can be used to eliminate interactions, there may be a substantial capital and operating cost advantage for high-quality public transportation compared to today's infrastructure intensive solutions.

Technology as a tool to enable intermodal and interjurisdictional service coordination - Technologies in the form of customer information systems, travel scheduling systems, and fare payment systems are providing an opportunity to improve public transit services via digital information and coordination. Historically, the physical presence of transit facilities and, to some extent, standardization of technologies across systems, as well as regionalization of service provision, were strategies that benefited travelers by virtue of facilitating both an awareness of and an opportunity to conveniently use a network of transit services. The ability to use technology to understand the full array of service opportunities and provide convenient information and fare payment offsets the need for standardizing or consolidating systems. The criticality of having the physical presence of rail as an assurance of service availability and, to some extent, service coverage, for example, is diminished when smartphone apps can provide sufficient information to enable travelers to conveniently plan a multimodal multijurisdictional/multi-operator trip. This can reduce the bias towards service standardization and regionalization of operations and increases the opportunity for the infrequent traveler to understand the transit options available and not be intimidated from taking more complex multimodal/multi-vehicle trips that currently might be unrecognized, intimidating, or inconvenient.

\section{Technology as a tool to improve the quality and cost-effectiveness of demand-responsive services -}

Paratransit or demand-responsive services always have provided operational challenges in that these more-specialized services struggle to be efficient in terms of capital and operating expenditures per passenger trip or passenger mile due to the lower density of demand and the need for providing curbto-curb services or special accommodations for mobility aids. Technology enables improved logistics for these services and potentially enables a spectrum of service providers to be engaged in paratransit services, in which the economies of scale and spectrum of vehicles and service providers can more optimally match the unique needs of various travel markets. For example, many agencies operate large numbers of vehicles capable of handling wheelchairs and mobility aids, which are then specified for any travelers who could be handled in a smaller, different type of vehicle. Technology offers the opportunity to effectively deploy a spectrum of vehicles best prescribed to match traveler needs, potentially coordinate service provision across providers and agencies, thus capturing logistics efficiencies, and use logistics to optimize trip scheduling and assignment.

\section{Policy Issues of Critical Importance to Public Transportation}

The prospect of new technologies influencing public transportation, including current trends regarding TNCs and certainly including the prospect of automated vehicles in the future, can have very profound impacts on public transit as we know it. The public transit industry has the challenge of positioning itself so as to leverage technologies within public transportation and position the industry to adapt to the inevitable changes that will accompany these technologies in a manner that represents their 
stakeholder interests, but, most importantly, strives to provide improved mobility that is so critical to the quality-of-life and economic functioning of the economy. Towards this end, some specific issues have emerged that merit the attention of the industry. Each of these is addressed briefly below.

\section{Strive to understand/monitor the impact of technology on travel behavior.}

The public transportation industry and stakeholders can play a role in collecting, synthesizing, and disseminating information about the pace of deployment of various travel-behavior-influencing technologies and the emerging evidence of their consequences on travel behavior and, subsequently, on overall society. This should include information about best practices and impacts of technologies deployed within public transportation, including automated fare collection, camera systems, wireless communications, and information on technology aids for driver operations. Driver operation technology aids include vehicle guidance systems, warning systems, visibility improvement systems, etc. In addition, information regarding TNCs, bikeshare, carshare, and vehicle automation demonstrations also should be monitored. Building a body of evidence as to the pace of deployment, issues and lessons learned during deployment, their consequence to the traveling public, and their subsequent impacts will be of value to the industry. The public transportation stakeholders' policy and program responses will benefit from objective information regarding the nature and consequences of technology deployments within both public transit and the competing and complementary modes.

\section{Define transit's role/opportunities as technologies change the range of mobility options and their characteristics for the traveling public.}

Public transportation stakeholders should engage in activities that help define the roles transit can take in the emerging field of mobility. This will include articulating the role of transit services in contexts where they remain critical, including:

- High travel volume locations in which large vehicles and trains of vehicles provide high capacity in limited space and minimize curb space/station space requirements relative to smaller vehicle alternatives.

- The provision of door-to-door assisted services for some paratransit travelers.

- The critical role of public transportation in ensuring affordable mobility for the financially-challenged market. Public transit generally has a $100 \%$ capital subsidy and approximately $70 \%$ operating subsidy for services in the US, which enable many persons of limited means to have access to mobility that may not be affordable with market-based rates for the alternative mobility concepts being envisioned. This role of providing a safety-net mobility option for significant shares of the population is

To the extent that alternative mobility options undermine the provision of public transportation as we know it, mechanisms will need to be in place to ensure access to mobility for those with resource constraints. This is arguably one of the most critical roles of transit and will require significant stakeholder engagement moving forward. 
critical. To the extent that alternative mobility options undermine the provision of public transportation as we know it, mechanisms will need to be in place to ensure access to mobility for those with resource constraints. This is arguably one of the most critical roles of transit and will require significant stakeholder engagement moving forward.

In addition, the public transportation industry should define potential role opportunities for a redefined public transit industry as the mobility world changes. Potential public transportation role opportunities include:

- Administrator/facilitator of affordable mobility options for segments of society that cannot currently afford personal vehicles and are unlikely to be able to afford full-priced mobility services. This could range from provision of services to subsidization of private sector services to user side subsidies.

- Provide a third-party interface or alternative mechanism for trip scheduling and fare payment for those segments of society not able to afford or use apps and debit/credit payment systems.

- Serve as a coordinator/administrator/facilitator/regulator of mobility services in situations in which the public is unwilling to delegate mobility provision exclusively to the private sector.

\section{Position transit to address emerging policy issues.}

A number of policy issues and critical concerns are emerging as various parties observe the changes in transportation and speculate on critical issues going forward. Public transit stakeholders may desire to formulate policy responses or other action plans to address these concerns.

The impact of automation on transit labor - The prospect of automated vehicle operation immediately raises the issue of the impact on transit operating labor. As noted, driver labor is a significant share of the labor force for public transportation. Speculative reactions have included everything from the expectation that labor's political power will preclude the elimination of operator positions for transit vehicles to scenarios in which the vehicle driver position would be redefined as something of an onboard customer service representative.

The impact of automation on transportation as well as the broader economy will have significant impacts on labor. Public transportation will not be alone in addressing the workforce implications of this transition. Similarly, the impact of automation on public transportation will be modest relative to the potential impact on freight transportation and other service and manufacturing employment categories faced with automation replacing jobs. Thus, public transportation is unlikely to receive unique attention from policy-makers.

There is significant risk to public support for public transportation if public transportation refuses to take advantage of the opportunity for improved service and mobility by favoring preservation of traditional employment for operators. However, it is important for public transportation stakeholders to recognize that a drivers' functions go beyond guiding the vehicle and include oversight of fare collection and 
customer behavior while in the vehicle and providing customer information. How these functions will be handled in the absence of an onboard operator will provide a challenge for public transportation going forward. Similarly, the public's reaction to driverless vehicles in broad deployment will be worth monitoring closely. Although there is extensive history of driverless vehicles in public transportation operation, it is less clear how this might play out as driverless vehicles operate in the full spectrum of sometimes harsh environments in which public transportation services are provided. Decisions to provide remote visual oversight of transit vehicle and passenger conditions might result in one choosing to characterize transit applications as piloted vs. automated operations.

Additional integration of automated capabilities within public transportation vehicles and systems also will impact the workforce requirements of public transportation agencies. Public transportation stakeholders will have to establish mechanisms whereby human resource constraints are not a limitation to the ability of public transportation to attract a technology-savvy workforce so as to be able to fully take advantage of technologies.

The effect of technologies on long-range planning and infrastructure investment - One of the most critical issues facing transit stakeholders as well as the broader transportation planning community relates to how long-range planning and capital investment decision-making have been, or should be, impacted by the presence of emerging technologies and the travel options they make available. Specifically, numerous communities across the country are planning for or evaluating major capital fixed-guideway public transit investments whose success may be impacted by the presence of alternative mobility options. The criticality of reflecting on these issues relates to both the magnitude of the cost of these commitments and the fact that these assets are very long-lived. These fixed-guideway commitments may well have extensive economic life remaining at points in time when new travel options compete with them, potentially cannibalizing their markets and rendering the investments less productive than envisioned in the planning stages.

One of the most critical issues facing transit stakeholders as well as the broader transportation planning community relates to how longrange planning and capital investment decision-making has been, or should be, impacted by the presence of emerging technologies and the travel options they make available.

The reality of this challenge already is apparent, as various media and stakeholders have challenged the merits of long-range capital-intensive rail projects based on the prospect that automated vehicles will cannibalize their markets and/or could offer a lower-cost, less government-subsidy intensive means of providing mobility options for future travelers. In addition to being direct competition, these travel options could influence development patterns, further undermining the relative attractiveness of transit-oriented development patterns.

This challenge creates the prospect that uncertainty will undermine progress on developing mobility capacity or create critical problems if the dependence on automation to solve mobility problems does not materialize in the same timeframe envisioned by some forecasters. Public transportation 
stakeholders have to address this challenge in a responsible fashion to retain credibility with the public as responsible stewards of public resources. Among the strategies that might make sense are reviewing project evaluation strategies and the methods for treatment of uncertainty in forecasts, careful exploration of the scale of the market and the ability of mobility services to accommodate the target market vs. dependence on large transit vehicles, and stronger differentiation between proven highvolume markets vs. aspirational projects dependent upon significant future growth.

Methods available to planners to help mitigate these risks might include the following:

- Explicitly assess uncertainty and risk in the alternatives evaluation process. This might include robust scenario analysis and engagement of expert panels and reviewers to address risk and uncertainty.

- Specify mobility improvement strategies that are inherently more flexible by virtue of the life cycle of system components and the adaptability of the infrastructure and service concepts. This might include strategies such as BRT in which vehicle lives are less than half that of rail vehicles and each replacement cycle can incorporate the newest guidance, propulsion, safety, and other technology and features.

- Include alternatives in which technology is used to optimize the operation of public transit and perhaps other automated vehicles on non-exclusive travel ways operated to ensure high performance mobility. Such concepts could provide preferential high performance for transit vehicles yet enable sharing the infrastructure cost and capacity across other vehicle types (freight and personal vehicles). These scenarios accommodate continued evolution of vehicle propulsion and automation features in shorter-lived vehicles (rather than typically long-lived rail cars) while relying on technology to ensure safe and high-speed operation in non-exclusive vehicle deployments.

- Evaluate different timing options for project implementation as part of the uncertainty assessment. In some instances, projects are proposed to meet longer-term travel needs that may or may not materialize, yet agencies seek current commitments, often as part of a system plan attempting to provide geographic equity and political appeal to various constituencies. By precluding premature commitments to highly-prescribed projects but perhaps taking steps to ensure the capability to subsequently implement them (i.e., preservation of right-of-way), this strategy enables reevaluation of the best course of action closer to implementation such that then-current conditions can be fully integrated into the evaluation.

\section{The Path Forward}

The significance of new technologies to transportation is so important that the single most critical need is for public transit stakeholders to engage in exploring the opportunities and implications that are now occurring and may materialize in the future. The ability to have a place at the table as investment, policy, regulatory and other decisions are being made at all levels of government requires the public 
transportation community to be engaged and knowledgeable of trends and prospects. The public transit workforce, transit passengers, and the general public that provides the financial support for public transit will all expect well-thought-out, fact-based (where possible), and open communications regarding technology deployment in transportation.

Technology deployment in transportation offers the potential for significant benefits to the traveler and society; however, those benefits will come with many consequences to travelers, the workforce, and the general public. There is a strong public interest in monitoring and, most probably, influencing the direction of technology deployments to ensure that the public interest is served and that the public interest (not just market behaviors and the pace of technology evolution) is critical to the path forward. Fundamental considerations such as equity across population groups, environmental consequences, safety impacts, workforce impacts, and others merit strong oversight.

The path forward also requires perhaps the most significant breaking down of modal silos in transportation that has ever occurred. At the extreme, this means not even thinking about technology change from the perspective of the impacts on public transportation, but rather from the perspective of the impacts on mobility. Whereas traditional public transit stakeholders may remain involved in discussions of the impacts of automation and technology deployment, the stakeholder community, over time, may be reorganized around mobility-related objectives rather than modes or technologies.

Finally, the nature of the changes is such that we are destined to have far greater uncertainty regarding transportation options, behaviors, and impacts going forward. These dynamics need to be accommodated in the breadth of transportation planning and investment decision-making for the future. Positioning plans and investments to accommodate uncertainty will be a critical element of responding to emerging technologies in transportation. 


\section{Selected Bibliography}

American Public Transportation Association (APTA), "Integrated Mobility/Transformative Technologies, APTA Policy Framework/Principles," adopted by APTA Board of Directors, October 3, 2015, http://www.apta.com/passengertransport/Documents/PT_02-

08_16_Connecting\%20Sectors_Part\%20I_in-depth_integrated\%20mobility.pdf.

The Atlantic, CITYLAB, "What Will Happen to Public Transit in a World Full of Autonomous Cars?" January 2014, http://www.citylab.com/commute/2014/01/what-will-happen-public-transit-worldfull-autonomous-cars/8131/.

“Autonomous Vehicles' Disruptive Potential for Transit," Surface Transportation News, 147, January 2016, http://reason.org/news/printer/surface-transportation-news-147.

Baldwin, Roberto, "Self-Driving Buses Will Be a Big Part of the Transit Puzzle," @strngwys, January 2016, http://www.engadget.com/2016/01/01/self-driving-buses-will-be-a-big-part-of-the-transit-puzzle/.

Conerly, Bill, "Self-driving Cars Will Kill Transit-oriented Development," Forbes, August 8, 2016, http://www.forbes.com/sites/billconerly/2016/08/08/self-driving-cars-will-kill-transit-orienteddevelopment/print/.

Grabar, Henry, "Is Uber Killing the Public Bus, or Helping It?" Slate, September 12, 2016, http://www.slate.com/blogs/moneybox/2016/09/12/how_cities_can_user_uber_bikeshare_and_ca rshare_to_supplement_trains_and.html.

Hutchinson, Robert, "Driverless Cars: What Could Possibly Go Wrong?" Harvard Business Review, January 2016, https://hbr.org/2016/01/driverless-cars-what-could-possibly-gowrong?utm_source=feedburner\&utm_medium=feed\&utm_campaign=Feed\%3A+harvardbusiness+ \%28HBR.org\%29.

Mistele, Bryan, CEO, INRIX, "Sound Transit's Expansion Will Be Obsolete before It's Built," Seattle Times, July 9, 2016, http://www.seattletimes.com/opinion/sound-transits-expansion-will-be-obsoletebefore-its-built/.

Muoio, Danielle, "This Self-Driving Bus Could Radically Change Public Transportation," Business Insider.com, August 22, 2016, http://www.businessinsider.com/andreas-mink-mercedes-future-busis-semi-autonomous-fuel-efficient-2016-8? $r=U K \& I R=T$.

Spross, Jeff, "Why Replacing the Bus with Uber is Actually Pretty Smart," THE WEEK, August 16, 2016, http://theweek.com/articles/642980/why-replacing-bus-uber-actually-pretty-smart.

University Transportation Research Center, "The Expanding Transportation Network Company ‘Equity Gap': Adverse Impacts on Passengers with Disabilities, Underserved Communities, the Environment and the On-Demand Workforce," September 2016, http://www.whosdrivingyou.org/wpcontent/uploads/2016/08/Equity-Report-FINAL-11232642.pdf. 
"Urban Transit's Uncertain Future," NOVA NEXT, January 2016, http://www.pbs.org/wgbh/nova/next/tech/urban-transits-uncertain-future/.

Walker, Alissa, "Can Self-Driving Technology Save the Bus?" CURBED, July 28, 2016, http://www.curbed.com/2016/7/28/12285810/self-driving-autonomous-bus-vehiclestransportation.

Waylen, Miki, "How Will the Sharing Economy Affect Public Transit?" Metro Magazine, August 2, 2016, http://www.metro-magazine.com/blogpost/714709/how-will-the-sharing-economy-affect-publictransit.

\section{Related CUTR Resources}

Gregg, Rob, and Brian Pessaro, National Bus Rapid Transit Institute, "Vehicle Assist and Automation (VAA) Demonstration Evaluation Report," FTA Report No. 0093, Federal Transit Administration, January 2016, https://www.transit.dot.gov/research-innovation/vehicle-assist-and-automation-vaademonstration-evaluation-report-report-no-0093.

National Center for Transit Research, "Evaluation of Automated Vehicle Technology for Transit," prepared for Florida Department of Transportation, January 2015, http://www.nctr.usf.edu/wpcontent/uploads/2015/10/77975-508-Version.pdf.

National Center for Transit Research, "Evaluation of Automated Vehicle Technology for Transit - 2016 Update," prepared for Florida Department of Transportation, April 2016, http://www.nctr.usf.edu/wp-content/uploads/2016/04/79060-21-AVT-for-Transit-Update.pdf.

Polzin, Steven E., "Implications to Public Transportation of Autonomous or Connected Vehicles," White Paper, November, 2013, http://www.automatedvehicleinstitute.org/pdf/TAVI_1PublicTransitPolzin.pdf. 